\title{
AMALLISE DO SONETO "ENTRE A RAIZ E A FLOR" DE JORGE DE LIMA "
}

\author{
SIGRID RENAUX * *
}

\section{"ENTRE A RAIZ E A FLOR"}

Entre a raiz e a flor: o tempo e o espaço, e qualquer coisa além: a côr dos frutos, a seiva estuante, as fôlhas imprecisas, e o ramo verde como um ser colaço.

Com o sol a pino há um súbito cansaço, e o caule tomba sôbre o solo de aço; sobem formigas pelas hastes lisas, descem insetos para o solo enxuto.

Então é necessário que as borrascas venham cedo livrá-la da cobiça que sobre e desce pelas suas cascas;

que entre raiz e flor há um breve traço: - silêncio do lenho, - quieta liça entre a raiz e a flor, o tempo e o espaço.

Analisaremos êste soneto tratando-o em seus quatro niveis de descrição linguística: fonético, morfológico, sintático e semântico.

- Trabalho final apresensado so professor de Liserafura Brasileira: Alfredo Bosi, como requisito para o obtençāo de crédircs, sob "A peesla de Jorge de Lima". São Paulo, Janeiro 1973.

* Sigrid Poula Moria Lange Scherrer Renaux - Lieenciada em Leiras Neolatinas * Anglo. Germśnicas 6 Mestre pela Universidade de Sāo Paulo (1974) com a Dissertasāo Word, Image and Symbol in H.D.'s Early Nafure Poetry. Publica na revista Lotras desde 1971 e na Univeraidade Federal do Paraná exerce as funçōes de Auxiliar de Ensino de LIngua e Literatura Ingle. so. 
Tentaremos depois uma integraçāo final que possibilite a explicação de um processo de significação. A delimiłação dos diversos níveis na análise não será rigorosa, pois involuntàriamente, ao explicar um nivel, penetra-se em outro.

\section{NIVEL FONETICO}

Este soneto (do italiano "um pequeno som"), apesar de apresentar a estrufura clássica de catorze versos, todos decassilábicos, já mostra uma variante quanto à rima final, cujo esquema é diferente do tradicional soneto petrarquiano:

1.० quarteto: abca

2. quarteto: aacb

1.० terceto : ded

$2 .^{\circ}$ terceto : aea

A textura vocálica destas rimas é a seguintes:

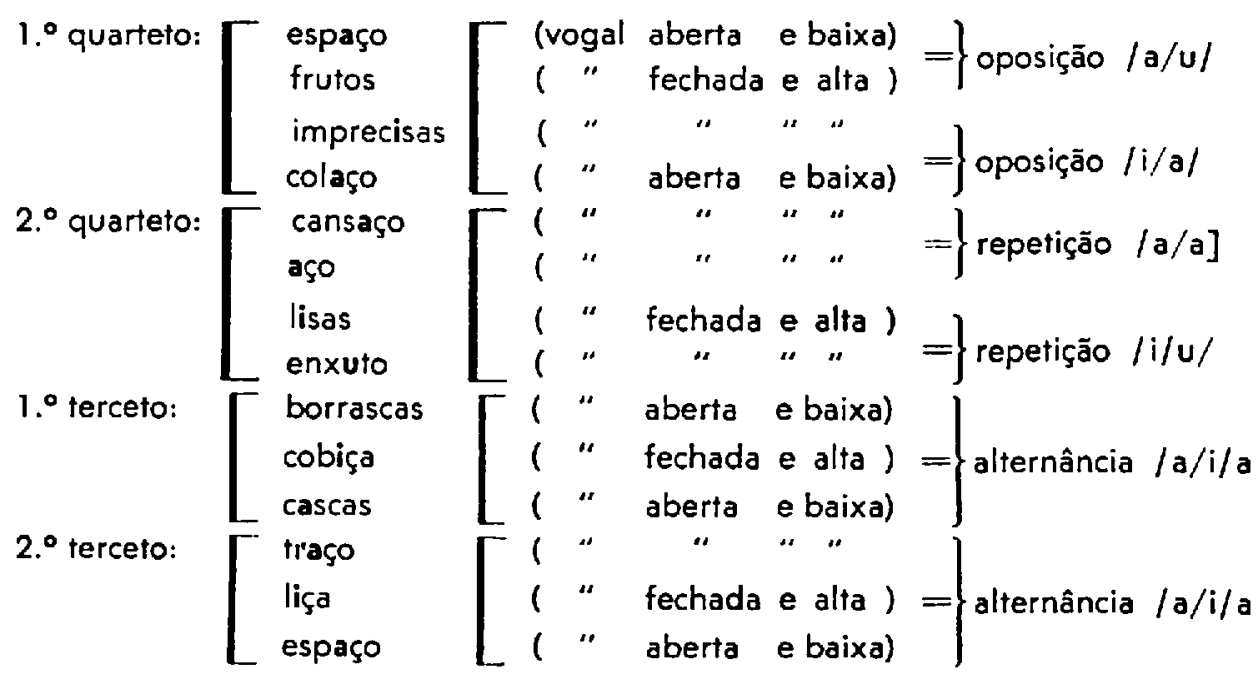

Teriamos então seis rimas em "aço", duas em "isas", duas em "ascas", duas em "iça" - todas rimas consoantes - e duas em "uto(s)" - uma rima toante. Nota-se também uma oposição nas rimas finais, entre a vogal aberta e baixa /a/ com as vogais fechadas e altas /i/ e /u/, (nos versos 1-2 e 3-4), uma repetiçăo (nos versos 5-6 e 7-8) e uma alternância (nos versos 9-10-11 e 12-13-14).

Estas variaçōes também se encontram no interior do soneto, mas de um modo mais brando, pois o contraste nas silabas acentuadas é mais entre sons médios e altos, ou médios e baixos: 


$$
\begin{aligned}
& \text { v. } 1-/ i / / o / / e / / a / \\
& \text { v. } 5-/ 6 / / i / / u / / a / \\
& \text { v. } 2-/ \hat{i} / / \mathrm{e} / / \hat{o} / / \mathrm{u} / \\
& \text { v. } 6-/ a u / / \tilde{o} / / \hat{o} / / a / \\
& \text { v. } 3-/ \hat{i} i / / \tilde{a} / / \hat{o} / / \mathrm{i} / \\
& \text { v. } 7-16 / / \mathrm{i} / \mathrm{a} / \mathrm{i} / \\
& \text { v. } 4-/ \tilde{a} ; / \hat{e} / / \hat{e} / / a / \\
& \text { v. } 8-/ e / / e / / 6 / / 0 / \\
& \text { v. } 9-/ \text { ão/ } / a / / a / \\
& \text { v. } 12-/ i / / \hat{o} / / e / / a / \\
& \text { v. } 10-/ \hat{e} / / a / / i / \\
& \text { v. } 13-/ e / / \hat{e} / / i e ́ / / i / \\
& \text { v. } 11-/ \delta / / e / / a / \\
& \text { v. } 14-/ i / / 6 / / e / / a /
\end{aligned}
$$

Como se pode observar por êste esquema, temos repetições das mesmas vogais acentuadas, tanto em posição horizontal, como vertical, como também em posiçōes contrárias ou cruzadas, (como também oposições entre médias e altas, médias e baixas, etc).

- Toda esta textura vocálica, acentuada pelo contraste nas rimas finais, faz sobressair a qualidade musical do soneto.

Quantos às consoantes (e vogais átonas), observamos o seguinte:

\section{1.' quarteto:}

v. 1 - A vibrante / $r$ / no começo de "raiz" e no fim de "flôr" $\mid \mathrm{r} /$, estão em posiçōes opostas, como consoantes extremas de dois elementos extremos. $O / z /$ sonoro de "raiz" parece abrandar um pouco a tônica aguda /i/, como a lateral / // que precede a fricativa /f/ no grupo consonantal / fl/ de "flor" também daria um abrandamento à palavra. Quanto a "o tempo o o espaço", as oclusivas surdas $\mid t / / p / / p /$ seguidas das fricativas surdas $/ \mathrm{s} /$, parecem pôr mais em evidência o prolongamento da nasalada /e/ e principalmente o encontro das vogais médias em $/ 0 / \mathrm{e} / \mathrm{o} / \mathrm{e} / \mathrm{o} / \mathrm{e} / \mathrm{o} /$, como também de tônica $/ a /$ seguida da fricativa surda $/ \mathrm{s} /$, e este prolongamento traz uma certa lentidão na articulação de "o tempo e o espaço" (que poderia exprimir o infinito que os conceitos dessas duas palavras nos surgerem. Este procedimento intensifica-se no verso final, quando "o tempo e o espaço" fecham o verso e o poema).

v. 2 - Aqui já predomina a aliteração da oclusiva surda / $/ \mathrm{em}$ "qualquer coisa", mas êste primeiro segmento do verso, apesar das oclusivas, é suavizado pela presença da lateral /1/ em "além" e da nasal $/ \mathrm{m} /$, além do $/ \mathrm{z} /$ sonoro em "coisa": A aliteração da oclusiva / $\mathrm{k} /$ serviria para introduzir a enumeração das partes da planta, que também é iniciada pela oclusiva / $\mathrm{k} / \mathrm{em}$ "côr", que por sua vez rima com "flor".

v. 3 - Nova repetição da fricativa surda /s/ em posições va- 
riadas que, intercaladas com fricativas sonoros $/ z /$, predominam sôbre as oclusivas $/ 1 /$. Os ditongos /ei//ae/ e uã/ de "seiva estuante", além das duas fricativas surdas /s/ seguidas de duas oclusivas surdas $/ t /$, daria uma certa ondulação ou continuação melódica às palavras, que lembraria a própria ondulação da seiva percorrendo-a planta toda.

v. 4 - A alteração da oclusiva /k/ lembra a do verso 2, em "como" e "colaço"; temos também uma rima interna "ver(de)" e "ser"; e a aliferação de "seiva" e "ser", a repetiçāo da fricativa surda /s/ em "colaço", mais a repetiçāo da vibrante /r/ prolongando e unindo o verso, em "ramo", "verde" e "ser", também serviria para relacionar todas estas partes e qualidades da planta, com o "ser colaço" (collacteu = individuos criados com o leite da mesma muther: irmão), que se alimenta da mesma seiva, dando então já uma segunda dimensão à planta, comparada ao ser humano, em sua vitalidade.

Mas as repetições anteriores irão aparecer no $2^{\circ}$ quarteło:

v. 5 - A fricativa surda /s predomina em "sol, "súbito" e "cansaço"; aliteraçāo da oclusiva surda /k/ em "com" e cansaço"; a sílaba átona /bili de "súbito" seria um abrandamento da silaba tô. nica /pi/ de "pino". A proparoxitona em "súbito" seguida de duas pós-tônicas aceleraria o rítmo desta palavra, que, seguida da prétônica de "cansaço" faria o rítmo cair novamente. As sílabas átonas estão precedidas de consoantes oclusivas, e as tônicas das fricativas surdas $/ \mathrm{s} /$, com exceção de pino. Nota-se também que as oclusivas $/ \mathrm{t} / \mathrm{b} / \mathrm{k} /$ estão cercadas pelas fricativas surdas $/ \mathrm{s} / \mathrm{em}$ "súbito cansaço". E as oclusivas / $k$ / e as fricativas /s/ estão em posiçōes inversas em "com o sol" e "súbito cansaço".

v. 6 - Contínua a aliteraçāo de $/ k_{i} / \mathrm{e} / \mathrm{s} /$ do verso anterior, em "caule", "sobre", "solo" e "aço". Por sua vez /k/ /t/ /p/ (oclusivas) opōem-se à fricativa /s/ em "caule tomba" e "sobre o solo de aço", assim como a aliteraçäo de "caule" e "cansaço" parece unir as duas palavras, pois o cansaço é do caule. A repetição das vogais precedidas pela fricativa /s/ dos versos 5 e 6 em "sol". "súbito", "cansaço" "sobre", "aço" continua:

v. 7-8: temos então "sobem", "descem", "insetos", "solo", "enxuto" (variante). Temos também uma oposição nos versos 7 e 8 entre duas oclusivas sonoras em posições contrárias e duas fricativas surdas /sb/ e /ds/ em "sobem" e "descem"; as repeliçōes do som /as/ em posição final átona de "formigas", "pelas" "lisas", como da tônica /i/ em "formigas" e "lisas" e a variante "insetos" e "enxuto" seriam quase como uma rima interna. 
Esta repetição (11 vezes) da fricativa /s/ (aspereza) serviriam para tematizar a implacabilidade do sol, e a aridez do solo, o mal provocado pelos insetos à planta, enfim, a própria luła que se trava entre os elementos da nafureza: sol, solo e insetos contra a planta, - que é reforçado pela grande repetição das oclusivas $/ k / / t / p /$ $/ b /$, com seus sons surdos e secos (com exceção do /b/, que é sonoro).

\section{1. terceto:}

v. 9. - As oclusivas / $\mathrm{k} /$ estão entremeadas pelas fricativas $/ \mathrm{s} /$, $\mid z /$ em "necessário", "que", "as borrascas". $0 / r /$ (duplo), reforçado pelas oclusivas / b/ e / $k$ / mais o /a/ aberto repetido em "borrascas" dá uma abertura e aspereza máximas a essas palavras. E as duas tônicas /sá/ e /ás/ estão em posiçōes inversas entre as fricativas $/ \mathrm{s} /$.

v. 10 - Temos repetição da fricativa /s/ em "cêdo" e "cobiça", uma oposição entre uma lateral mais átona /li/ e uma oclusiva mais tônica / bi/, aliteração da lateral /// em "livrá-la" e um maior contraste entre as duas sílabas acentuadas /á/ e /i/, como no verso 8. As fricativas /s/ também estão cercando as laterais em "cêdo livrátla da cobiça".

v. 11 - Nova aliteração do / $\mathrm{k} / \mathrm{em}$ "que" e "cascas" (que percorre todo o soneto), além da repetição de "que sobe e desce" dos versos 7, 8 e 9 (verbos no singular, apenas), cuja característica contrastiva já foi mencionada acima: $/ s b / \times / d s /$ (poderia-se dizer que essa oposição das oclusivas e fricativas em posições imensas lembraria a oposição dos próprios verbos). A repetição da mesma sílaba em "cascas", torna a palavra tão clara e áspera como seu par "borrascas". A repetição da sflaba /as/, três vezes como átona e uma como tônica, além de reforçar a sonoridade do $/ a /$, como ocorreu também no verso 7 , contrasta com a predominância das vogais mé$\operatorname{dias} / \delta / \mathrm{e} / \mathrm{lé} / \mathrm{le} /$ (tônicas e átonas) no início do verso. Alternam-se, como em todo o soneto, as oclusivas e fricativas, com uma característica $/ k /$ e $/ \mathrm{s} /$ em posições alternantes: "cobiça" $/ \mathrm{k} / \mathrm{s} /$ : "borrascas" /sk//s/: "cascas" k/sk/s.

Também no plano fonético continua a predominância das oclu. sivas $/ \mathrm{k} / \mathrm{e} / \mathrm{s} /$, como no $2 .^{\circ}$ quarteto, e isto ligaria o 1,0 terceto ao quarteto anterior, com seus sons duros e ásperos, também na respectiva significação de coisas desagradáveis, que continuam a sobrevir à planta. 


\subsection{Terceto:}

v. 12 - Predomínio dos grupos consonantais /tr/ /fl/ (pares distintivos( / br/e $/ \mathrm{tr} /$, que já apareceram isoladamente nos versos $1(\mathrm{tr} / \mathrm{fl} /) 2(/ \mathrm{fr} /), 3(/ \mathrm{pr} /), 6(/ \mathrm{br} /)$ e $10(/ \mathrm{vr} /)$.

No segundo segmento do verso 12 teríamos outro par distintivo entre /br/ (oclusiva sonora) e /tr/ (oclusiva surda). Estes grupos consonantais däo continuidade ao som pela vibrante $/ r /$. "Breve" "fraco" também têm a mesma estrutura fônica inversa: "breve" ocl. sonora, vibrante, tônica média aberta, fric. sonora, átona final média) e "traço" (ocl. surda, vibrante, tônica aberta, fric. surda, átona final média).

v. 13 - Temos uma continuação sonora, uma harmonia imitativa em "o silêncio do lenho" onde predominam as vogais obscuras $/ 0 / \mathrm{i} / \mathrm{e} / \mathrm{io} / \mathrm{o} / \mathrm{e} / \mathrm{o} / \mathrm{que}$, com as mesmas fricativas $/ \mathrm{s} / \mathrm{e}$ laterais /1/ se entremeando, além das nasalizaçōes, nos dariam: /osile/ /siodole/ o. No segundo segmento do verso 13 , temos duas oclusivas $/ \mathrm{k} / \mathrm{l} / \mathrm{se}$ opondo a uma lateral /1/ e a uma fricativa $/ \mathrm{s} /$, seguidas de vogais quase repetidas $/ i e ́ / a / e / i / a /$, o que deixa as paslavras "quieta liça" muito bem delimitadas e claras, além da aliteração de "lenho" e "liça" (ambos de madeira: tomando "liça" no seu sentido original de paliçada de madeira).

$$
\text { v. } 14 \text { - ver verso } 1 .
$$

Conclusäo: todos esses recursos utilizados pelo poeta, nas sonoridades, em suas semelhanças e contrastes, repetiçōes, aliteração, versos em que todas as palavras têm a a tônica na primeira sílaba (verso 6), além da repetição das mesmas palavras ou até de versos inteiros (o primeiro e último do soneto), criam um "clima", como diz Waltensir Dutra na sua Introdução Geral da Obra Poética, ${ }^{1}$ em que o poeta valoriza a palavra como som, e não só como significado lógico. E isto nos leva de novo ao significado da palavra "soneto", um pequeno som.

- Após havermos examinado as rimas, e as características fonéticas, passaremos a tratar do ritmo.

\section{RITMO}

O ritmo, que para $\mathrm{Bri}^{2}$ é a repetição periódica dos elementos no espaço, é de modo geral lento e regular neste soneto:

1 LIMA, Jorge de. Obra Complete, Rio de Janeiro, Aguilar, 1958. y. I, p. 35.

2 BRIK, Ossip. "Ritmo e Sintaxe". In: Teoris do litersturs: formalistse russes. Popto Alegro, Globo, 1970, p. 135-6. 


$$
\begin{aligned}
& \text { 1.० quarteto }-4 \text { acentos (icto na } 4^{\circ}, 6^{\circ}, 8^{\circ} \text { e } 10^{a} \text { ): } v .1 \\
& \text { (" " } \left.4 .^{a}, 6 .^{a}, 8 .^{a} \text { e } 10^{a}\right): \text { v. } 2 \\
& \text { (" } \left." 2 .^{a}, 4 .^{a}, 6 .^{a} \text { e } 10^{\circ}\right): \text { v. } 3 \\
& \text { (" } \left." 2 .^{a}, 4^{\alpha}, 8 .^{a} \text { e 10. }{ }^{a}\right) \text { : } v .4 \\
& \text { 2. } .^{\circ} \text { quarteto }-4 \text { acentos (" } " 2^{\circ}, 4 .^{\circ}, 6^{a} \text { e 10. } .^{\circ} \text { ) v. } 5 \\
& \text { (" } \left." 2 .^{\circ}, 4 .^{a}, 8^{\circ} \text { e } 10^{\circ}\right): \text { v. } 6 \\
& \text { (" } \left." 10^{\circ}, 4 .^{a}, 8 .^{a} \text { e } 10^{a}\right): \text { v. } 7 \\
& \text { (" } " 1 .^{a}, 4 .^{a}, 8 .^{a} \text { e 10.9): v. } 8
\end{aligned}
$$

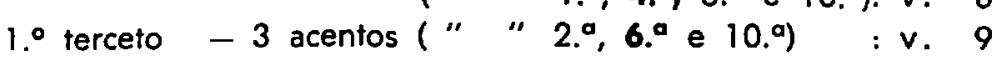

$$
\begin{aligned}
& \text { (" } " 3 .^{\circ}, 6 .^{a} \text { e 10.a) : } \text { ) } 10 \\
& \text { (" } " 2 .^{a}, 4 .^{a} \text { e 10.9) : v. } 11 \\
& \text { 2. } \left..^{\circ} \text { terceto }-4 \text { acentos (" " } 4 .^{\circ}, 6 .^{\circ}, 8^{\circ} \text { e } 10 .^{\circ}\right): \text { v. } 12 \\
& \text { (" } \left." 3 .^{a}, 6 .^{a}, 8 .^{a} \text { e } 100^{\circ}\right): v .13 \\
& \text { (" } \left." 4 .^{\circ}, 6^{\circ}, 8 .^{\circ} \text { e } 10^{\circ}\right): \text { v. } 14
\end{aligned}
$$

(O negrito das sílabas acentuadas indica onde recai o icto obrigatório, sendo os outros, acentos secundários).

Esta relativa liberdade com que Jorge de Lima acentua os decassílabos, fazendo os acentos recaírem exatamente sôbre as pala vras mais expressivas do soneto, coincide exatamente com a opinião do Brik, ${ }^{3}$ para quem o verso deve ser uma unidade rítmica e sintática, que é a particularidade distintiva da lingua poética: uniram-se neste soneto estas duas leis, porque o complexo rítmico e sintático aparecem simultâneamente, criando uma estrutura semântica e rítmica especifica:

En trea ra íz ea flôr: o tem poeoes pa ço, e qual quer coi saa lém: a côr dos fru tos, e sei vaes tuan te, as fô lhas im pre ci sas eo ra mo ver de co moum ser co la ço,.

Com o sol a pí nohaúm sú bi to can sa ço, eo cau le tom ba sô breo so lo dea ço; so bem for mi gas pe las has tes li sas, des cem in se tos pa rao so loen $x u$ to.

En tão é ne ces sá rio queas bor ras cas venham cê do li vrá-la da co bi ça que so bee des ce pe las su as cas cas

queen tre ra iz e flôr háum bro ve tra ço:

o si lên cio do le nho, - quie ta li ça

en trea ra $f z$ e a flôr, o tem poeoes pa ço. 


\section{1. quartefo:}

v. 1 - Há uma pausa semântica obrigatória no meio do verso, indicada pelo sinal de pontuaçāo (:) o que coloca em evidência o que vem antes, que é "flôr", palavra em que recai o icto obrigatório deste verso, o que a torna muito significativa, dentre as outras palavras acentuadas: "raiz", "tempo" e "espaço". O rítmo diminui um pouco após o sinal de pontuação, pela lentidão na articulação das palavras no segundo 'segmento (ver pg. $2, v .1$ ).

v. 2 - 0 mesmo fato se repete aquí a ênfase dada à palavra "além", em que recai o icto, combinado com nova pausa semântica, com o sinal de ponfuação (:). O primeiro segmento seria pronunciado mais lentamente que o segundo, quase como uma continuação da idéia de "tempo e espaço", (unidos pela conjunçāo "e"). Também estão acentuadas as palavras "coisa", "côr" e "frutos".

v. 3 - A ondulação rítmica de "seiva estuante" também apressaria um pouco o ritmo e o icto recai desta vez na palavra "estuante", onde haveria uma pausa apenas no icto, pois a silaba átona / te/ apesar da vírgula, está ligada à sílaba seguinte por elisão, o que continuaria a linha melódica. "Seiva", "fôlhas" e "imprecisas" são as outras acentuadas.

v. 4 - O icto recai em "verde" e "ser", mas o verso seria lido como um todo, pois a comparação já une o primeiro segmento ao segundo. "Ramo" e "colaço" já recebem acentuação secundária.

\section{2. quarteto:}

v. 5 - A aceleração do ritmo em "súbito", coincide com o icto, pois como já foi visto no nivel das consoantes, o ritmo cai em "cansaço" o que valorizaria o adjetivo precedente. As outras palavras acentuadas são "sol", "pino" e "cansaço".

v. 6 - Há uma pausa semântica após "tomba", em que recai o 1. icto, pois a sonoridade da nasal ími dá uma continuidade ao som, apesar das oclusivas, que por sua vez diminuem o ritmo do primeiro segmento. $O 20^{\circ}$ icto recairia sôbre "solo", com as palavras "caule" e "aço" acentuadas secundariamente. A continuidade das fricativas /s/ 
por sua vez apressaria um pouco o ritmo ajudada pelas elisōes.

v. 7 - 8: aqui o acento se desloca para a primeira sílaba, para destacar a posição inicial dos verbos, que, anteponde-se ao sujeito, chamam atenção sôbre a atividade dos insetos e formigas, que é intensa, em seu movimento ascendente e descendente. Estes dois versos em si, têm os acentos exatamente iguais, na $1 .^{a}, 4 .^{a}, 8 .^{a} 10^{a}$, recaindo 0 icto no verso $7 \mathrm{em}$ "formigas", além das acentuadas "sobem", "hastes", "lisas", e no verso 8 o icto recai novamente em "insetos", além de "descem", "solo" e "enxuto",. Ambos os versos seriam lidos no mesmo ritmo, sem variaçōes, pois ambos indicam a atividade dos insetos no caule.

\section{1. terceto:}

v. 9 - O padrão rítmico já é diferente no $10^{\circ}$ terceto, que, pelo 10 fato de ter apenas três acentos (o icto recaindo em 'ne-

11 cessário", os outros dois sendo em "entāo" e "borrascas"), e pela sua construção sintática complexo, além da ausência de sinais de pontuação, deveriam ser lidos sem pausas no meio do verso, formando o terceto um todo. $O$ ritmo nesse terceto já se tornaria quase coloquial, com o poeta interferindo: "então é necessário que..."

\section{2. terceto:}

४. 12 - Volta-se ao esquema inicial de 4 acentos, em "raiz", "flor" (em que recai o icto), "breve" e "traço". O icto coincide novamente com uma pausa semântica entre os dois segmentos do verso e mais uma pausa no final, indicada por (:).

v. 13 - A vírgula após o primeiro segmento, acentuada por um travessão, por si só já retém bastante o ritmo deste último terceto, que seria mais lento, com o icto em "lenho" e os outros acentos em "silêncio", "quieta" e "liça".

v. 14 - Repetição do verso 1, mas com a pausa não tão acentuada após o icto, pois a (.) muda o significado do verso 14 , e êle formaria um todo e o ritmo seria pausado, mas com uma entoação diferente do verso 1.4

4 Cf. "nada, nadador!" e Nada, nadador", em "Poema do Nadador". In:Obra Comple. 1. de Jorge do Lima. Vol. I-p. 334. 
- Esta retenção ou aceleração na leitura de certas palavras do soneto, além de os acentos cairem nas palavras mais significativas do poema, dá uma grande riqueza e maleabilidade ao rítmo, o que concorda novamente com $\mathrm{Bri}^{\mathrm{a}}$, para quem o impulso rítmico é anterior ao resultado do movimento.

O soneto rìtmicamente estaria unido pela leitura mais lenta do $1 .^{\circ}$ quarteto e $2 .^{\circ}$ terceto (com pequenas variações internas), que poderiam expressar a estaticidade em que se encontra a planta; como também o ritmo se intensifica um pouco no $2 .^{\circ}$ quarteto e $1 .^{\circ}$ terceto que indicariam a dinamicidade, a luta da natureza hostil contra a planta, o que no nivel dos sons já foi confirmado pela predominância de sons sêcos e ásperos; enquanto no último terceto, retorna-se à serenidade inicial.

Então o som, transformando-se em ritmo e significação, nos levaria aos niveis mais profundos, pois a sonoridade fala do rítmo interior do poeta, que aqui foi muito bem acomodado na fôrma do soneto.

\section{NIVEL MORFOLOGICO}

E interessante notar que todas as palavras do soneto são de origem latina, o que seria mais um fator para integrar o soneto dentro dos moldes clássicos: a sensação que se tem diante de um soneto é de alguma coisa pronta e acabada, onde tudo foi medido e a peça adquiriu uma existência inalterável. Então a camada visiva do soneto nos informa de uma ordem e contenção clássicas, de um mundo em que a realidade singular se submete a uma realidade universal ${ }^{\circ}$.

- 1. quarteto se destaca pela dominância de substantivos (raiz, flôr, tempo, espaço, coisa, frutos, seiva, folhas, ramo, "ser"), e os respectivos adjetivos que thes valorizam o sentido (estuante, imprecisas, verde, colaço). Todos os substantivos (excetuando "tempo", "espaço" e "coisa") são sintagmas que fazem parte do mesmo paradigma "planta". "Qualquer" (adjet. indef.), "coisa" e "'além" (adv. de lugar, o que o ligaria a "espaço", como também significando algo mais, em acréscimo), são três palavras que formam um bloco separado dentro da exatidão que os substantivos referentes à planta denotam, pois "qualquer coisa além" é uma expressão vaga, indefinida, que está além do tempo e do espaço que estão entre a raiz e a flôr.

Há também uma ausência total de verbos, pois estamos a ver a planta ainda num mundo edênico, onde há apenas beleza e paz.

5 BRIK, Ossip. "Ritmo..." p. 132.

7 Ver adianta ciraço de Greimas, nota 15. 
que dá abertura ao quarteto são dois sinais de pontuação (:), o primeiro quase como um substituto do verbo "haver", e o segundo introduzindo uma enumeração, mas ambos servindo também para explicar a frase (nesse caso, os substantivos) que os precede.

A planta é particularizada pelo uso dos artigos definidos, o que coloca ainda mais em evidência o único artigo singularizante "um ser colaço", o que tornaria êste membro "marcado" no soneto, quando a planta começa a se metaforizar.

- Estas características morfológicas então tematizariam o mundo da planta, sua vida física, mas num plano estático.

2.ं quarteto: já apresenta verbos, um em cada verso, os dois primeiros referindo-se à planta (singular), os dois últimos referindose aos insetos (plural), e esta diversidade já foi apresentada no pla. no rítmico, com a deslocação do acento para a $1^{\circ}$ sílaba nos versos 7 e 8. Mas temos ainda o predomínio dos substantivos (sol, cansaço, caule, solo, formigas, hastes, insetos, solo) e alguns adjetivos (súbito de aço, lisas, enxuto). Todos os substantivos dos versos 5 e 6 estão no singular e são masculinos (inclusive "pino", aqui como expressão adverbial, e "de aço", aquí como adjet. qual.), e esta similaridade condiz perfeitamente com a repetição dos mesmos sons oclusivos e fricativos, o que foi visto no plano fonético: esta coincidência nos dois planos serviria para tematizar a planta, já em luta contra a natureza adversa, sua fraqueza, sua queda ou declínio ("tombar" nas suas duas acepçōes).

Nos versos 7 e 8 , predomina o plural (formigas, hastes, insetos), que caracterizaria o mundo dos insetos, em contínuo movimento, nutrindo-se da planta. Mas o quarteto estaria unido pela idéia central de que a planta é fraca e sujeita à decadência e ao mal (parasitas), além da dinamicidade que a presença de verbos dá ao $2 .^{\circ}$ quarteto, em comparação com o $1 .{ }^{\circ}$.

Todos os verbos também estão no presente, indicando atemporalidade, que no $1 .^{\circ}$ quarteto também se manifesta pela ausência de verbos. Quanto aos artigos, predominam de novo os definidos, pondo em evidência o único singularizante que é "um súbito cansaço" (cf. "um ser colaço") que uniria novamente o conceito de planta cansada, ao de "ser humano cansado".

As qualidades que o solo apresenta, "de aço" e "enxuto", bem como a expressão "a pino" (inclemente, vertical) que se refere ao

7 Vale o peno lembrar a esso respaito o seminário baseado em Gaston Bachelard, no qual foi dito que árvors e o hamem sāo os dois únicos scres verticais. Ver também poema do Blake, nota 12 . 
sol, também formariam uma unidade, pois são as condiçōes adversas que a planta encontra, na própria natureza, que no quarteto anterior havia sido tão benigna. (Cf. o $2 .^{\circ}$ quarteto com o plano fonético: a secura e aspereza dos sons oclusivos e fricativos).

1. terceto: caracteriza-se pela presença maciça de verbos, todos novamente no presente (ind. ou subj.), numa construção sintática complexa, além da presença das conjunçōes (então, que), que marcariam o processo do poeta falando( mesmo que impessoalmente: "é necessário") o que também criaria um contraste entre a linguagem poética dos versos acima e a linguagem quase coloquial dêste terceto.

Os único substantivos são "borrascas", "cobiça" e "cascas", to. dos em posição final (tendo em comum a ocl. $/ \mathrm{k} /$ e a fric. $/ \mathrm{s} / ; \mathrm{cf}$. plano fonético), e femininos.

Esta diferença no plano morfológico já foi verificado também no ritmo, pois a língua falada (mais rápida) difere da poética (mais pausada, no caso dos dois quartetos acima): temos uma sequência quase sem interrupções, formando novamente um bloco: o poeta "invoca" (se é permitido aquí usar este termo) as tempestades, para libertar a planta da cobiça, do mal que the causam os parasitas: é a marcha para a solução.

Chama atenção támbém o adjetivo posessivo "suas", o único em todo soneto, que afualiza melhor que "de" as relações de posse entre "planta" e "cascas".

2. terceto: após a conjunçāo "que", causal, (= porque), temos novamente o predomínio dos substantivos (raiz, flôr, traço, silêncio, lenho, liça, tempo, espaço) e dois adjetivos (breve e quieta), o que nos levaria de volta ao esquema inicial, pois o único verbo (há) é estático, no sentido de "existir". Desta vez, no v. 12, "raiz" e "flor" aparecem sem os artigos definidos, o que generalizaria aqui os termos, aplicáveis a toda e qualquer planta. Mas no último verso, os termos aparecem novamente definidos, como no $v$. 1 do qual êle é a repetição, com a diferença da vírgula, em vez dos dois pontos.

Mas os antigos definidos ainda dominam neste terceto, com novamente o mesmo singularizante "um" em "um breve traço", outro elemento marcado neste soneto, como os dois outros nos ver$\operatorname{sos} 4$ e 5 .

O $2 .^{\circ}$ terceto está unido ao $1 .^{\circ}$ quarteto, não só pela repetição de palavras e até de versos, como também pela complementação que "um breve traço" dá à idéia inicial, e a sinonímia de "o silêncio do 
lenho" e "quieta liça" que exprimem o estado atual em que se encontra a planta.

Esta volta ao esquema inicial, mas ao mesmo tempo sua complementação, tematizaria a vida da planta, como sendo apenas um breve traço unindo o começo ao fim, que se dá em silêncio e solidão.

* - A extrema simplicidade do vocabulário empregado por Jor. ge ne Lima dá uma grande clareza visual ao poema, reforçada pela forma do soneto, que é bem delimitada, e isto permite uma leitura fácil do mesmo, no sentido linear. Ao mesmo tempo, a metáfora implícita em quase todos os substantivos e adjetivos nos fornecerá posteriormente uma leitura do poema em profundidade.

\section{NIVEL SINTÁTICO}

O soneto compreende os seguintes enunciados:

1. quarteto: $1 \mathrm{EN}$

2. quarteto: 4 EN simples

1.० terceto: 1 EN complexo

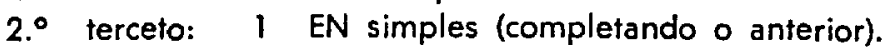

Teriamos então os seguintes tipos de sintagmas

Entre a raiz e a flor (SC): o tempo e o espaço, (SN) e qualquer coisa além (SN): a côr dos frutos (SN) a seiva estuante ( $\mathrm{SN}$ ), as fôlhas imprecisas (SN) e o ramo verde (SN) como um ser colaço (SN).

Com o sol a pino (SC) há (SV) um súbito cansaço (SN), e o caule (SN) tomba (SV) sôbre o solo de aço (SC); sobem (SV) formigas (SN) pelas hastes lisas (SC), descem (SV) insetos (SN) para o solo enxuto (SC).

Então é necessário (SV) que as borrascas (SN) venham cedo (SC) livrála (SV) da cobiça (SN) que sobe e desce (SV) pelas suas cascas (SC);

que entre raiz a flor (SC) há (SV) um breve traço (SN): o silêncio do lenho (SN), - quieta liça (SN) entre a raiz e a flor (SC), o tempo e o espaço (SC).

- Nota-se então que no $1 .^{\circ}$ quarteto predominam os SN, no 2. quarteto há um perfeito equilíbrio entre os SN (4), SV (4) e SC (4), no $10^{\circ}$ terceto predominam os SV complexos, e no $20^{\circ}$ terceto 
novamente domínio dos SN, (3), em equilíbrio com os SC (3), com apenas Um SV.

Observa-se além disso uma permuta perfeita nos versos 5 e 6 da posição dos sintagmas: SC SV SN e SN SV SC; enquanto nos versos 7 e 8 eles estão colocados em posições paralelas: SV SN SC e SV SN SC. Poderíamos então considerar este $20^{\circ}$ quarteto como sintáticamente o mais perfeito do poema, pelo equilibrio encontrado, no nível sintagmático.

Fazendo uma rápida análise do terceto mais complexo, notamos que se trata de um período composto por subordinação (em contraposição ao $2 .^{\circ}$ terceto, onde temos apenas enunciados simples - coordenação): "E necessário" seria a oração principal, "que as borrascas venham cedo livrála da cobiça" oração subordinada substantiva subjetiva, e "que sobe e desce pelas suas cascas" oraçāo suborl dinada adjetiva. E $\circ 2 .^{\circ}$ terceto seria uma subordinada adverbial causal.

- Entrando um pouco na teoria dos paralelismo e acoplamentos de Levin ${ }^{8}$, que assentam não só nas correspondências sintägmáticas mas também fonológicas e semânticas, teríamos:

v. 7 e 8: acoplamento sintático e semântico (os SV indicando movimento, os SN indicando um gênero de insetos, e os SC indicando lugar).

v. 5 e 6: paralelismo sintático (em posições invertidas): é interessante observar que o SC "com o sol a pino" (subst. concreto e "ao àlto", em posição vertical) se acha em posição cruzada com o SC "sôbre o solo de aço" (subst. concreto e "em baixo", horizontal), en. quanto no cruzamento dos SN temos um concreto e um abstrato (caule e cansaço).

Outros exemplos de paralelismos ou acoplamentos:

Sintático e semântico: $\left[\begin{array}{l}\text { sôbre o solo de aço } \\ \text { para o solo enxuto }\end{array}\right.$

$\left[\begin{array}{l}\text { pelas hastes lisas } \\ \text { pelas suas cascas (adjet. em posições } \\ \text { investidas) }\end{array}\right.$

B LEVIN, Samuel Linguistic Strueturs in Postry. The Hague, Mouton, 1982. 
-sobem formigas

descem insetos

cobiça que sobre e desce (repetição

metaforizada do

-paralelismo dos versos 7 e 8 )

Fônico e sintático:

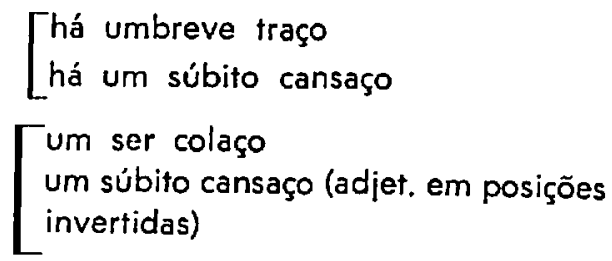

- Temos também repetições dos verbos: "ho" (v. 5 e 12), "sobe'm, descem" v. 7 e "sobe e desce" v. 11.

- Segundo Jakobson, a tessitura gramatical da poesia apresenta simetrias e anti-simetrias, estruturas balanceadas, formas que se equivalem e contrastantes, e todo êste instrumental poético nos faz perceber o efeito poético e a carga semântica desses mecanismos gramaticais, o que coincide parcialmente com a teoria de Levin ${ }^{10}$ para quem o caráter que distingue a linguagem poética seria a distinção dos signos por pares, em projeçōes sintáticas paralelas.

Jakobson também fala em "comparação identificadora e dife. renciadora"11. Como exemplo da primeira, teríamos:: "e o ramo verde como um ser colaço", e também "silêncio do lenho - quieta liça", que por sua vez são o "breve traço".

Mas como estas estruturas superficiais atualizam uma estrutura mais profunda do espírito, tentaremos ir além dos acoplamentos e correspondências, procurando uma síntese da significação tołal, se bem que não possamos completar a aparição e significado do soneto em toda sua multiplicidade.

\section{NIVEL SEMĀNTICO:}

Como o soneto em princípio desenvolve um símbolo, o que acontece com os grandes sonetistas renascentistas, românticos ou mesmo parnasianos, em que há uma perfeita convergência de todos os detalhes, vamos procurar as contribuiçōes que os níveis anteriores ao nivel semântico possam trazer, para em seguida examinar o "simbolo", o sentido do soneto.

9 JAKOBSON, Roman. "Poesia do Gramática - Gramática da Poesia". In: Linguistica. Pobfica Cinema. São Poulo, Perspectiva, 1970. p. 73.

10 LEVIN, Lingulstic

11 JAKOBSON, p. 78. 
O 1.* quarteło já se inicia com duas palavras que evocam não apenas a origem, e o climax de uma planta, mas o desabrochar do ciclo vital, que não pode ser definido apenas pelo desab:ochar aquí e agora entre o tempo e o espaço, mas tem algo que ultrapassa tudo isso, essa contingência do ciclo existencial. Raiz e flor se situam em polos opostos, pois entre ambos está o tempo que a planta precisa, para chegar da raiz à flor, e o espaço necessário para o caule, que une a raiz à flor. Mas há algo a mäis numa planta, consequências do seu desenvolver no tempo e no es;aço, e que é tôda sua vitalidade e beleza, caracterizada pelo cromatismo dos frutos e ramos, a seiva que é seu líquido nutritivo e ao mesmo tempo lhe dá vigor, e que é também "estuante", arden'e como todo ser com vida, enquanto as fôlhas, que são o prolongamento das hastes, ainda não têm forma definida, porque a planta ainda está em crescimento; "vede" nos lembra não apenas côr, mas também viço, que mais tarde virá a ser vigoroso (verde $=$ viride). E finalmen'e se alinge o momento em que a planta se personifica, ao ser comparada com "um ser colaço". Ela é um ser vivo, como o ser humano, seu irmão colaço.

Os conceitos abstratos que "tempo" e "espaço" evocam em nós, continuam em "e qualquer coisa além", pois "coisa", além de ser algo indefinido, traz também conotação de mistério; e basta lembrar a frase "E Deus criou todas as coisas" o que une esta palavra aos frutos, ramos, seiva e fôlhas que são as partes integrantes da planta, como o ser humano, que também é fértil.

Neste primeiro quarteto as palavras significativas (em que recai o icto) seriam exatamente "raiz" e "flor", com sua conotação não só de ápice, pois se chega sempre da "raiz" (nascimento) à "flôr" (fim, morte, mas como transcedência para algo melhor); mas entre começo e fim, está algo "além", e que é a vida física em sua pujança, em seu ardor, como a de um ser humano. Temos então uma trajetória positiva, ascendente, vertical, e en're esses dois polos está o transcendental, o ilimitado, que é a vida humana.

A ligação com o 2. quarteto se estabelece exatamente quando se chega ao ápice da vida da planta, em que ela é comparada ao homem, e que é transposto no $2 .^{\circ}$ quarteto (o ápice) no "sol a pino", no seu ponto mais alto; e exatamente na plenitude de sua vida física, vem um "súbito" cansaço, inesperado, pois tanto a planta como o homem estāo sujeitos às leis da natureza. O ser é frágil e declina, "tomba". E a natureza que havia sido tão benigna à planta, o sol the dando luz e calor, o solo que the servia de base e de alimento, agora estão adversos à planta, pois ambos são: o sol, incle- 
mente (a pino) e o solo, endurecido (de aço) (enxuto), seco e árido. Esta aridez já havia sido vista no plano fonético, como a luta que se trava entre a natureza e a planta também no plano fonético-morfológico.

O movimento aumenta gradativamente, partindo de "haver", ainda estático no sentido de "existir", característica do quarte'o anterior, como no sentido de "fatalidade impessoal", não desejada pela vítima, pois o cansaço é consequência do sol a pino. Então a açāo do verbo "tombar" também seria involuntária, consequência por sua vez do cansaço, enquanto o movimento dos parasitas é voluntário, contínuo, ilimitado como os próprios insetos (que também saem do solo), para lhe tirar a seiva, maltratando a plan'a. A planta (vida humana) é fraca, cansa, s é sujeita à decadência, pois tomba, e ao mal (cobiça dos insetos): desvanece-se a beleza, as hastes estão "lisas".

A mesma cposição (no sentido de limite de dois polos) achada entre "raiz" e "flôr", contínua com "sol" e "solo" (ver nivel sintag. mático) e também o movimento ascendente do sol e descendente da planta é continuado pelos inse'os que sobem e descem. O solo, por sua vez, nos lembra "espaço", enquanto o sol está associado à noção de "tempo"."'.

O 1. terceto por sua vez se acha ligado ao anterior pela conjunção "então": a expectativa que nasceu com "raiz" aumenta cada vez mais, até chegarmos ao final do $2^{\circ}{ }^{\circ}$ quarteto. Agora a solução se aproxima, e o poeta, como que afastado desta luta, fala: êle aceita e deseja que as borrascas, que castigam a planta, venham liberála (a água e a dor purificam) do mal, da cobiça.

Assim como a planta se submete ao castig'o das tempestades, também o poeta acha o sofrimento necessário, para atingir a purificação, a libertação do mal - enquanto o ser humano geralmente mal diz a dor, o mal. E novamen'e a natureza que era benéfica, enviando chuvas para nutrir o solo e a raiz da planta, primeiro envia o

12 Cf. poems de William Blake, "Sunflower": - Songs of Experionce:

Ah. Sun.flowerl weary of time,

Who countest the steps of the Sun,

Seeking after that sweet golden clime

Whare the traveller's journey is dene:

Where the Youth pined away with desire.

And the pole Virgin shrouded in show

Arise from their graves, and aspire

Where my Sun-flower wishes 10 go".

(Alids esta comparaçäo da drvore com a ser humano, achada em muitos poetas, aqul simbolizaria a spiraşăo do homem: preso j carne, como o girassol a terra, èle vira seu rosio como o girassol, em direçāo no sol, do infinito). 
sol inclemente, tornando o solo árido, e agora envia tempestades, demonstrando a dualidade da natureza, que dá vida e morte ao ser. E a planta vai sofrendo uma lenta transformação, já apontada por Maria Luiza Ramos, sua Fenomenologia da Obra Literária ${ }^{13}$, cuja trajetória positiva, ascendente, agora toma um sentido inverso, negativo: chegamos às "cascas" (parte exterior da planta, mas também no sentido de hastes sêcas, sem seiva). "Suas" atualizando o que sobrou de posse para a planta: o envólucro.

Finalmente o $2 .^{\circ}$ terceto, ligado so anterior pelo sinal de pon. tuação (i) e que se inicia com a conjunção causal "que, nos dá o desfecho: éntre o começo e o fim do ser vivo, está: a vida, que é apenas "um breve traço"; "flôr" aquí na acepção de morte como coisa positiva, não de fim, aventuraríamos dizer. $E$ ao tronco (lenho) estoico, sobram o silêncio e a solidāo, pois a liça, a arena de luta, foi abandonada. O "breve traço", a vida do caule, do ser humano, é breve tanto no tempo como no espaço, e o traço (metaforizando lenho e liça, já em si sinônimos) nos lembra tanto a verticalidade (do lenho) como a horizontalidade (de uma liça), o que poderia estar ideográficamente também representado pelo hífen antes de "quieta liça". Então o que permanece para o lenho, após as lutas e do sofrimento e purificação, é a estoicidade (o ser humano sofre em silêncio) e a solidão.

As palavras "breve", "silêncio", "quieta" também poderiam indicar o fim gradual do próprio soneto, já no seu último verso; e a mes. ma graduação achada entre os substantivos referentes à planta, achamos em grau menor também nos verbos (há um aumento de movimento até o fim do $10^{\circ}$ terceto, depois retornamos à estaticidade inicial), como nos adjetivos: "súbito" é mais violento e inesperado que "cedo" (advérbio), assim como "breve" e "quieta" (duração do silêncio no tempo) também atenuam e caracterizam o "traço", e o silêncio da liça, do lenho.

Em todo o poema o poeta apela aos nossos sentidos: visão, au. dição, tato, (poder-se-ia dizer até gosto - em frutos e sirva) e olfato (em flôr).

Mas é no verso final, no sentido do verso, 14, que a vida humana é projetada em abertura para o infinito, pois o contexto do 1. e do último versos, é diferente: pois o breve traço está não só entre a raiz e a flôr, mas também entre o tempo e o espaço. "Tempo" e "espaço" fecham materialmente o poema, pois são as pala-

13 RAMOS, Maria Luiza. Fenomenologia da Obra Literbria. Rio de Janeiro, Forense, 1972, p. 22! . 
vras finais, mas abrem semânticamente para a eternidade, para o infinito (já sugerido no plano fonético).

O úitimo terceto, segundo Riffaterre ${ }^{4}$, seria o micro-contexto do procedimento (o breve traço entre a raiz ea flôs, entre o tempo espaço, é vida humana) e todo o resto do soneto seria o macrocontexto. O soneto também é bi-isótopo (simbólico), segundo Greimas: ${ }^{15}$

1.) o destino da árvore

2) $\circ$ destino do homem

\section{(realidade singular) \\ = categoria classemática. (realidade universal)}

- Esta interpretação difere daquela dada por Maria Luiza Ramos, para quem o lenho seria morte, o fim da existência, se bem que ela se refere ao ciclo existencial, ao dizer que o poeta retoma o verso inicial. Mas êle o retomá em outro contexto, o que está claramente diferenciado pelos sinais de pontuação: (:) no verso $1,($,$) no$ verso 14. Neste ponto Riffaterre e Greimas também vāo além de Levin, pois o poema encerra um micro e um macro-contextos, além de ser bi-isótopo.

Resumindo, teríamos como o "sentido" do soneto:

1.० quarteto: a vida e o destino físico, material, do homem e de planta.

2. - quarteto: a vida humana é fraca, sujeita à decadência e ao mal.

1. - terceto: a dôr purificaria o ser, como antídoto do mal.

2. - terceto: a vida e o destino transcendente do homem: do nascimento à morte, a vida é um sofrer em silêncio, é estoicidade. O ser é finito (um breve traço), mas entre - nascer (raíz) e morrer (flôr) estão também a eternidade e o infinito: o ser humano é também transcendente, projetado no tempo e no espaço.

- Esta riqueza de alusōes semánticas, transportadas para "morte" (flor) como algo de positivo, de bom, pois projeta o ser para o transcendental, poderia ser associado a um contexto bíblico, uma constante na obra de Jorge de Lima. Além desse tema bíblico, poderíamos interpretar o soneto num sentido alegórico também (que não deve interferir com a interpretação principal): o próprio soneto é um "breve traço" (pois entre o princípio ou "raiz" do soneto e sua

14 RIfFAterre, Michael. Essais de Stylistique Structurale. Paris, Flammarion, 1971. 364 p.

15 GREIMAS, A. I. Sómentique Structurale Paris, Larousse, 1966, p. 97. 
conclusāo - chave de ouro - a "flor", há apenas um "breve tra. ço": as palavras, que proferidas sāo "breves" no tempo e que escri. tas sāo "breves" no espaço). Seria então um texto metalinguístico. Mas, assim como o ser vivo é transcendental, o soneto também 0 seria, pela poesia nele contida.

\section{RESUMO}

Partindo da "fo:ma" para chegar a "significaçäo", analisamos o soneto "Entre a Raiz e a Florr", de Jorge de Lima, em seus niveis linguisticos (fonético, morfologico, sin" tático e semânticol. Fizemos depcis una integração final, projetando o soneto, para um contexto biblico, alegórico e metainguistico. numa tentativa de eniquecer o pro. cesso de significaçāo.

\section{SUMMARY}

"Entre a raiz a florr" by Jorge de Lima: In ordu to proced An analysis of this sonnet at its linguistic leveis (Phonologie, Morphologic, Syntactic and Semantime) we start from its "form" to arrive at its "meaning". A final integration is then made, projecting the sonnet into a biblical, allegcrical and metalinguistic context, in an attempt to enrich the process of mesning.

\section{REFERENCIAS BIBLIOGRAFICAS}

BLAKE, William, Complele wrilings. London, Oxford University Press, 1969. $944 \mathrm{p}$. GREIMAS, A. 1. Sémantique structurale. Paris, Larousse, 1966. 262 p.

JAKOBSON, Roman, Linguistica. Podliea. Cinems. Sāo Paulo, Perspectiva, 1970. $208 \mathrm{p}$.

LEVIN, Samuel. Linguistic structures in poefry. The Hague, Mouton, 1962.

LIMA, Jorge de, Obra completa Rio de Janeiro, Aguilar, 1958, v. 1.

RAMOS, Maria Luiza. Fernomenologia da obra litorária. Rio de Janeiro, Forense. 1972. $254 \mathrm{p}$.

RIFATERRE, Michael. Essais de stylistique structurale. Paris, Flammarion, 1971. 364 p.

TEORIA da liseratuia: formalistas russos. Porto Alegre, Gobo, 1970. 279 p. 